\title{
Review of Microstrip Patch Antenna for Radiolocation Applications
}

\author{
Tutut Herawan1)
}

\begin{abstract}
The basic design of microstrip patch antenna consists of a metallic patch printed on a grounded substrate. The microstrip patch antenna can be easily understood by various approaches. These approaches can be verified in two categories viz., contacting and noncontact. In the contacting approach, the patch is straight fed with RF power by means of the contacting element such as microstrip line or coaxial line. Electromagnetic field coupling is done in the non-contacting method to transfer power between the radiating patch and the microstrip line. Microstrip line, Coaxial probe, Aperture coupling and Proximity coupling are the four most popular feeding techniques. Basics of the microstrip antenna, different feeding methods, and antenna constraints are presented through this literature survey.
\end{abstract}

Keywords: microstrip antenna, feeding techniques, radiation pattern, VSWR, EM

\section{Introduction}

A microstrip antenna includes two major sides of a metallic configuration one fitted on the dielectric substrate and ground plane on the further side of the substrate as displayed in Figure 1.1. Copper or gold is used for making a patch since they are eligible to make some probable arrangement. The radiating patch and the feed line are displayed generally on the dielectric substrate. There are various types of patch forms such as rectangular, circular, annular-ring, and Equi triangle. The patch antenna impression was major planned in the early 1950s[1]. The compatibility with integrated circuit technology, the ease of manufacture and small profile are the advantages of the microstrip antenna. Its main demerit is the fine bandwidth which is usually less than $5 \%$. The low profile benefit was mostly good for fast running vehicles such as missiles, aircraft, and space crafts. In order to make the analysis and performance estimation simpler and easier, there are various types of patch shapes such as rectangular, circular, annular ring and Equi triangle. Under the guidance of a dense dielectric substrate that has less dielectric constant, this offers higher bandwidth and improves radiation and efficiency. However, this configuration causes a large size of the antenna. In order to decrease the antenna size a higher dielectric constant is used.

Received(October 09, 2017), Review Result(1st: November 02, 2017, 2nd: November 28, 2017), Accepted(December 04, 2017)

${ }^{1}$ Dept. of Information Systems, University of Malaya, Malaya

email: tutut@ump.edu.my 


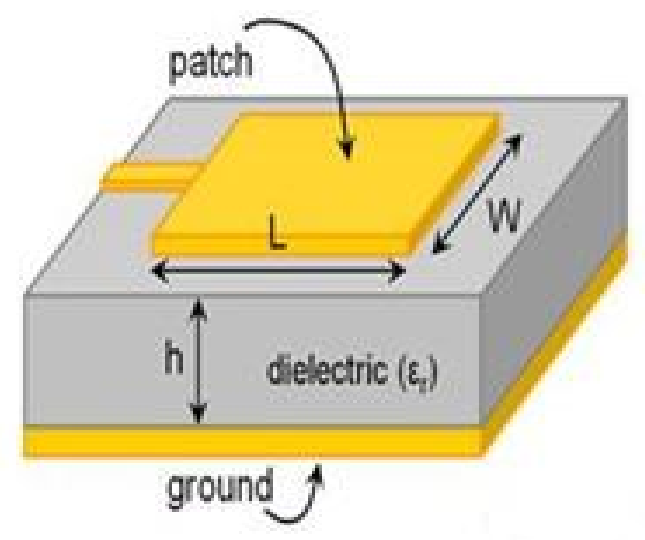

[Fig. 1] microstrip patch antenna structure

\section{Literature Review}

The texts on MPAs are huge, containing several research articles in archival journals. In the Distinctive Topic of IEEE Proceedings in 1992, titled "Antenna", Prof. D. M. Pozar wrote a review article on microstrip antennas[2]. In the review article published in the Henry G. Booker Memorial Issue in 1989[3], Lee predicted that "We can appear onward to sustained research in MPAs for quite some time to come." There were also numerous assessment articles, and records, and a limited list is given in [4-9]. Practically the microstrip antenna are made useful by the development of Printed Circuit Board (PCB), microwave techniques and many kinds of low-attenuating media materials [10-17].

\section{Feeding Techniques}

The function of the feed is to radiate through direct or indirect connection. The feed of microstrip antenna consists of various arrangements viz., offset microstrip line, coaxial feed, aperture coupling feed and proximity coupling feed. In fact, coaxial feeds and microstrip line are comparatively easier to fabricate. Coaxial feed is easily operated at $50 \Omega$ at several points. These points are obtained with the aid of a mathematical method.

\subsection{Microstrip (Offset Microstrip) Line Feed}

The figure 1.2 shows a conducting strip which is associated straight to the verge of the microstrip patch. The conducting strip is thicker than the patch. The benefit is that the feed can be easily engraved on the similar substrate to produce a perfectly balanced planer structure. Hence, this is an informal feeding technique since it offers simplicity in modeling and ease of fabrication and also in impedance matching. Surface waves 
and false feed radiation rises when the thickness of the dielectric material rises, which fetters the bandwidth of the antenna. It results in an undesirable cross polarization.

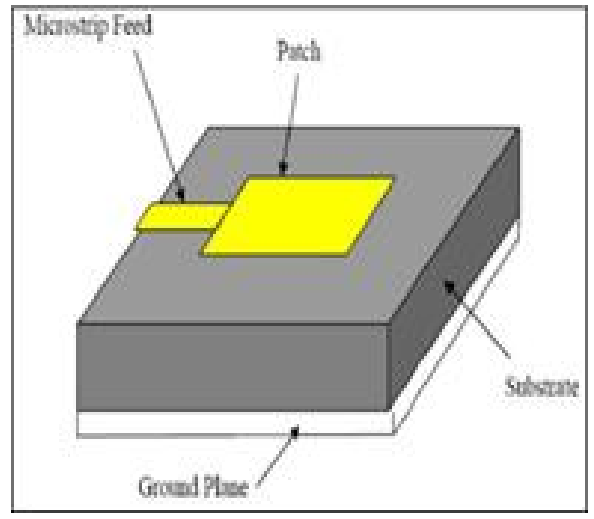

[Fig. 1.1] Microstrip line feed

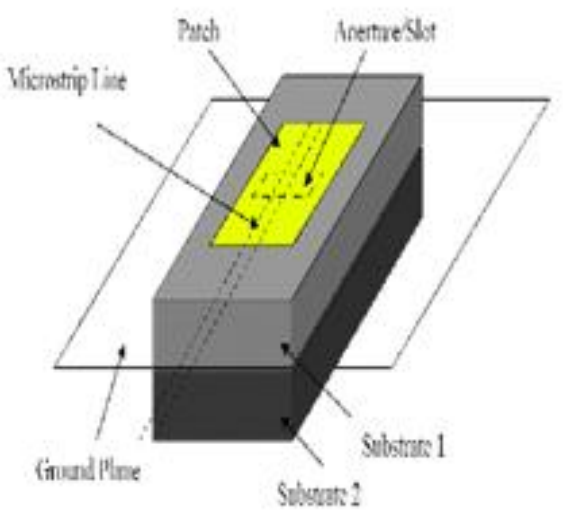

[Fig. 1.3] Aperture Coupled (EM) feed
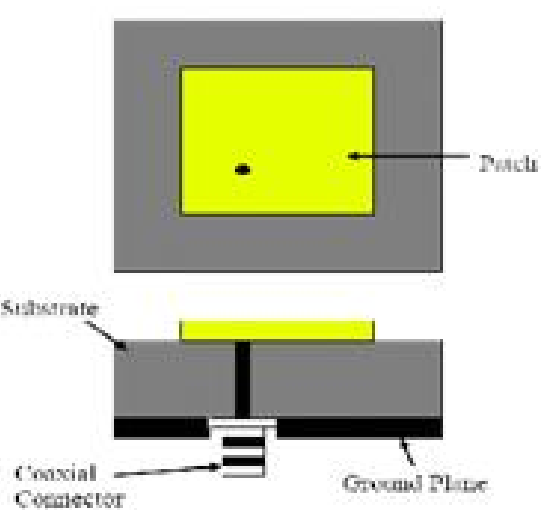

[Fig. 1.2] Coaxial feed

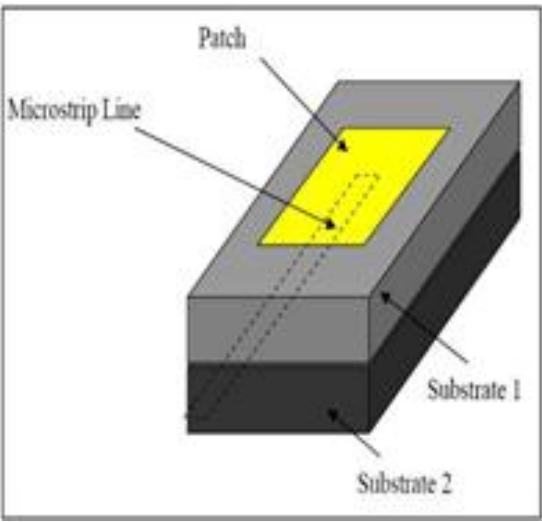

[Fig. 1.4] Indirect feed

\subsection{Coaxial Feed}

Another name of this technique is the probe feed and is one of the utmost mutual techniques. Figure 1.3 shows the outer conductor which is connected to the ground plane and the inner conductor of the coaxial connector extends through the dielectric and is soldered to the radiating patch. The merit of this feeding arrangement is that the feed can be situated at some location inside the patch in order to obtain impedance matching. This is informal to operate and has fewer radiation effects. The main demerit of this method is that it offers narrow bandwidth and is tough to operate.

\subsection{Aperture Coupled Feed}

Figure 1.4 shows the hard surface of the top of antenna substrate which contains the radiating microstrip 
patch element and the bottommost hard surface of the feed substrate contains the microstrip feed line. The width and the dielectric constant of these two substrates optimize the different electric function of radiation and circuitry. It is hard to manufacture due to several layers, which also leads to an increase in antenna thickness and this is the chief disadvantage of this feed technique.

\subsection{Proximity Coupled Feed}

Another name of this technique is electromagnetic coupling arrangement. Figure 1.5 shows the two dielectric substrates which are arranged in such a manner so that a fixed feed line is between the two substrates. The upper substrate contains the radiating patch. But this method is helpful since it provides the right feed radiation and a very high bandwidth. The two dielectric layers that need proper alignment are difficult to fabricate and is a major disadvantage. Also, the overall thickness of the antenna is increased.

\section{Antenna Parameters}

Return Loss, Voltage Standing Wave Ratio, Antenna Gain, Directivity, Antenna Efficiency, and Bandwidth are the different antenna parameters.

\subsection{Gain}

The gain is not an amount which can be well-defined in relations with physical quantity such as Watt or $\mathrm{Ohm}$. It is a dimensionless ratio. The gain of the antenna in a particular path is the amount of energy radiated in the provided direction as compared to the energy of an isotropic antenna that would radiate in the same direction under same input power. Gain is given by:

$$
\mathrm{G}=4 \pi \cdot \mathrm{U}(\theta, \Phi) / \mathrm{P}_{\text {in }}
$$

Where, $U(\Theta, \Phi)$ represents intensity in a particular direction and Pin is the input power.

\subsection{Radiation pattern}

A graphical demonstration of the comparative supply of the radiated power in space is known as Radiation pattern.

\subsection{Antenna efficiency}


The ratio of the complete power radiated by an antenna to the complete input power of the antenna.

\subsection{VSWR}

A new way to understand what method the system is matched, VSWR (Voltage Standing Wave Ratio) can be used. VSWR is the fraction of the maximum voltage and minimum voltage in the transmission line, and can be defined as follows:

$\operatorname{VSWR}=1+\rho / 1-\rho$,

where $\rho$ is the scale of $|\Gamma|$.

The reflection coefficient is nearly 0 when the system is matched, while the VSWR is nearly 1 .

\subsection{Return loss}

Return loss is defined as the power of the reflected signal in a transmission line. It can be computed by the following equation:

$$
R L(d B)=-20 \log 10 \Gamma
$$

The return loss is also stated as the S11 of the S-parameters and is given in $\mathrm{dB}$.

\subsection{Bandwidth}

Antenna bandwidth is the range of operational frequencies of the antenna nearby the resonance frequency.

\section{Study of antenna designing parameters}

The three crucial constraints for designing a rectangular microstrip Patch Antenna are as follows: Initially, the resonant frequency (f0) must be picked out correctly. The second essential constraint of the antenna is substrate width, the height of dielectric substrate (h). The third main parameter of good antenna project is a dielectric substrate $(\varepsilon r)$. A dense dielectric substrate which is having small dielectric constant is needed which delivers better efficiency, bandwidth, and radiation. The small amount of dielectric constant increases the fringing arena at the patch boundary and consequently lower the quality factor $\mathrm{Q}$ and increases the radiated power.

Patch is acted as a conductor. This configuration of the antenna having a length of patches L, thickness W, 
the height of dielectric substrate $\mathrm{h}$ and Loss tangent. The main project parameter is a dielectric constant of the substrate substance. These are located on an endless ground level.

The transmission line method is used to calculate the antenna parameters. [Balanis, 2005] [10].

\subsection{Width of the Patch:}

$$
W=\frac{\mathrm{c}}{2 \mathrm{f} \sqrt{\frac{\mathrm{gr}+1}{2}}}
$$

James et al., determine the antenna width in 1989, where, $\mathrm{c}=$ speed of light in free-space.

\subsection{Resonant Frequency:}

$$
f_{0}=\frac{c}{2 L_{e} \sqrt{\varepsilon_{r}}}
$$

The length Le, Effective length is given by,

$$
\mathrm{L}_{\mathrm{e}}=\mathrm{L}+2 \Delta \mathrm{L}
$$

The actual patch length, $\mathrm{L}$ is given as (Pozar et al, 1995):

The extended length $\Delta \mathrm{L}$ due to fringing effect is calculated by the following equation:

$$
\begin{aligned}
& \Delta L=0.412\left[\frac{\left(\varepsilon_{r \varepsilon f /}+0.3\right)\left(\frac{w}{h}+0.264\right)}{\left(\varepsilon_{r \varepsilon f /}-0.258\right)\left(\frac{w}{h}+0.8\right)}\right] \\
& \varepsilon_{\mathrm{reff}}=\frac{\varepsilon_{\mathrm{r}}+1}{2}+\frac{\varepsilon_{\mathrm{r}}-1}{2}\left(1+\frac{12 \mathrm{~h}}{\mathrm{w}}\right)^{-\frac{1}{2}}
\end{aligned}
$$

Where, $\mathrm{h}=$ Height of dielectric substrate

$$
\mathrm{W}=\text { Width of the patch }
$$

\section{Conclusion}

This paper presents a theoretical study on microstrip patch antenna and it concluded that lower power 
control capacity and lower gain can be surpassed by an array structure and inserted patch.

\section{References}

[1] G. A. Deschamps, Microstrip microwave antennas, presented at the 3rd USAF Symp. on Antennas, (1953).

[2] D. M. Pozar, Microstrip antennas, Proc. IEEE, vol. 80, no. 1, pp. 70 -91, (1992).

[3] K. F. Lee, Microstrip antennas Basic properties and some recent advances, J. Atmosph. Terrestrial Phys., vol. 51, pp. $811-818,(\mathbf{1 9 8 9})$.

[4] J.-F. Zurcher and F. E. Gardiol, Broadband Patch Antennas. Dedham, MA: Artech House, (1995).

[5] K. F. Lee and W. Chen, Eds., Advances in Microstrip and Printed Antennas. New York: Wiley Interscience, (1997).

[6] G. Garg, P. Bhartia, I. Bahl, and A. Ittipiboon, Microstrip Antenna Design Handbook. Dedham, MA: Artech House, (2002).

[7] K. L. Wong, Compact and Broadband Microstrip Antennas. New York: Wiley Interscience, (2002).

[8] G. Kumar and K. P. Ray, Broadband Microstrip Antennas. Dedham, MA: Artech House, (2003).

[9] Z. N. Chen and M. Y. W. Chia, Broadband Planar Antennas. New York: Wiley, (2005).

[10] Z. N. Chen and M. Y. W. Chia, "Broadband Planar Antennas, Design and Applications," John Wiley \& Sons, Ltd.

[11] FCC 802 Standards Notes, "FCC First Report and Order on Ultra-Wideband Technology," (2002).

[12] H. Oraizi and S. Hedayati, "Miniaturized UWB Monopole Microstrip Antenna Design by the Combination of Giuseppe Peano and Sierpinski Carpet Fractals," IEEE Antennas and Wireless Propagation Letters, vol. 10, pp. 67-70, (2011).

[13] R. Azim, M. T. Islam, "Compact Tapered-Shaped Slot Antenna for UWB Applications," IEEE Antennas and Wireless Propagation Letters, vol. 10, pp. 11901193, (2011).

[14] Constantine A.Balanis, Editor, "Antenna Theory: Analysis and Design, second edition" (1938)

[15] Sweety Jain, Pankaj Singh Tomar, G.S. Tomar, "Design \& Analysis of Proximity Fed Circular Disk Patch Antenna”, International Journal of Emerging Technology and Advanced Engineering Volume 2, Issue 10, pp 126-131, October (2012).

[16] P. Ranjan, GS Tomar, R Gowri, "Meta Material Loaded Shorted Post Circular Patch Antenna", International Journal of Future Generation Communication and Networking, Vol.9, No.10, pp.217-228, (2016).

[17] Vivek Singh Kushwah \& G.S. Tomar, "Design of Microstrip Patch Antenna using Neural Network", ICFAI Journal of Science \& Technology, Vol.5, No.2, pp 59-71, Jun (2009). 